\title{
Effect of resistant starch supplementation on blood lipids in metabolic disorder adults: A meta analysis of randomized controlled trials
}

\author{
Tingting Miao, ${ }^{1,4^{*}}$, Yun $\mathrm{Yu}^{2 \#}$, Haiting Hu${ }^{1}$, Jin $\mathrm{Sun}^{3,4}$, Mengjun $\mathrm{Cui}^{3}$, Aiguo $\mathrm{Ma}^{4}$, Mengyun Zhang \\ ${ }^{1}$ Department of Science and Education, Changzhou Maternity and Child Health Care Hospital Affiliated to Nanjing \\ Medical University, Changzhou 213003, Jiangsu, China; ${ }^{2}$ Department of Clinical Laboratory, Changzhou Maternity \\ and Child Health Care Hospital Affiliated to Nanjing Medical University, Changzhou, Jiangsu, China; ${ }^{3}$ School of \\ Food Science and Technology, Jiangnan University, Wuxi 214122, Jiangsu, China; ${ }^{4}$ Institute of Nutrition and \\ Health, Qingdao University, Qingdao 266071, Shandong, China; ${ }^{5}$ Department of Food Science, University of \\ Massachusetts, Amherst, Massachusetts, USA
}

${ }^{*}$ Corresponding author: Tingting Miao, Changzhou Maternity and Child Health Care Hospital affiliated to Nanjing Medical University, Changzhou 213003, Jiangsu, China; E-mail: miaott1986@163.com Tel:15151989887

"Tingting Miao and Yun Yu contributed equally to this work.

Received May 28, 2019; Accepted August 17, 2019

Resistant starch (RS) acts as insoluble fiber and by definition is resistant to enzymatic digestion in the small intestine and is non-viscous. The results of randomized controlled trials (RCTs) investigated that resistant starch(RS) supplementation on the effect of blood lipids in metabolic disorder adults have been inconsistent. The present meta-analysis aimed to quantitatively evaluate the effect of RS intervention on the concentration of blood lipids.PubMed, Cochrane, and Web of Science databases were searched up to July 2019. Mean differences were calculated on the effect of lipids by using a random-effects model. Pre-specified subgroup analyses were carried out to explore the sources of heterogeneity. Six studies (10 treatment arms) with 320 participants were identified. The result showed that RS supplementation had no significant effect on concentration of TC $\left(-0.28 \mathrm{mmol} / \mathrm{L}, 95 \% \mathrm{CI}:-0.68\right.$ to $\left.0.12 \mathrm{mmol} / \mathrm{L}, P=0.16, \mathrm{I}^{2}=94 \%\right), \mathrm{TG}(-0.42 \mathrm{mmol} / \mathrm{L}$, 95\% CI: -1.02 to $\left.0.19 \mathrm{mmol} / \mathrm{L}, P=0.18, \mathrm{I}^{2}=99 \%\right), \mathrm{HDL}(0.06 \mathrm{mmol} / \mathrm{L}, 95 \% \mathrm{CI}:-0.15$ to $0.27 \mathrm{mmol} / \mathrm{L}$, $\left.P=0.57, \mathrm{I}^{2}=96 \%\right)$ and LDL $\left(-0.17 \mathrm{mmol} / \mathrm{L}, 95 \% \mathrm{CI}:-0.70\right.$ to $\left.0.37 \mathrm{mmol} / \mathrm{L}, P=0.54, \mathrm{I}^{2}=94 \%\right)$. Subgroup analysis showed that there were decreased effect on TC concentration when RS was less than or equal to $30 \mathrm{~g}$, but increased effect on TG and LDL concentration when the dose of RS was more than $30 \mathrm{~g}$, and increased effect on TG in people who were overweight; no significant effect on HDL concentration no matter the dose of $\mathrm{RS}$, the intervention time or the disorder status of people.

Key Words: Resistant starch; Blood lipids; Meta analysis; Randomized controlled trials

\section{INTRODUCTION}

Resistant starch (RS) acts as insoluble fiber and by definition is resistant to enzymatic digestion in the small intestine and is non-viscous, but could be fermented and utilized by the microbiota in the colon. ${ }^{1}$ RS is classified into five subtypes (RS1-RS5), namely physically trapped starch, resistant starch granules, retrograded starch, chemically modified starch, and amylose-lipid complexes. ${ }^{2}$ Like other insoluble fibers, it is fermented in the colon by the microflora which releases carbon dioxide, methane, hydrogen and metabolically active short chain fatty acids (primarily acetate, propionate and butyrate) which are utilized by the colonic epithelium and enter the portal circulation. ${ }^{3}$

In the past several years, there has been continued interest in the physiological effects of resistant starch, since it might be an attractive source of non-caloric food with a more palatable character than insoluble dietary fiber. It is generally accepted that

This is an open access journal, and articles are distributed under the terms of the Creative Commons Attribution-NonCommercial-ShareAlike 4.0 License, which allows others to remix, tweak, and build upon the work non-commercially, as long as appropriate credit is given and the new creations are licensed under the identical terms.

For reprints contact: weda-h@weda-h.org

How to cite this article: Miao TT, Yu Y, Hu HT, Sun J, Cui MJ, Ma AG, Zhang MY. Effect of resistant starch supplementation on blood lipids in metabolic disorder adults: A meta analysis of randomized controlled trials. J ADV HEALTH 2019; 1(4): 70-84. 
RS replaced for digestible starch in the diet can lower serum cholesterol concentrations in normal or hypercholesterolemic conditions in animals. ${ }^{4-10}$ However, in humans, these findings are not yet fully supported. For example, the cholesterol lowering effect has not been found with normolipidemic subjects. ${ }^{11}$ Also,postprandial cholesterol lowering effect was not observed with RS supplementation in healthy adults, even though there was a decrease in postprandial TG concentration. ${ }^{12}$ It has been proposed that the cholesterol-lowering effect observed in animal models is attributed to the increased production of short-chain fatty acids (SCFA) in the large intestine. In human studies, a general rise in SCFA was often examined, ${ }^{13,14}$ however, there is no conclusive evidence that this is related to blood lipids performance.

Recently, several RCTs regarding RS supplementation on the effect of blood lipids have been published; however,the results are still inconsistent. In addition, there has been no meta-analysis of this matter so far. Therefore, to provide a more comprehensive, up-to-date assessment of RS supplementation, we conducted a meta analysis of RS supplementation on effects of blood lipids.

\section{METHODS}

\section{Design}

The study was designed in accordance with the Cochrane Handbook for Systematic Reviews of Interventions. ${ }^{15}$ We reported our results according to the Preferred Reporting Items for Systematic Reviews and Meta-Analysis statement. ${ }^{16}$ Two investigators (Tingting Miao and Yun $\mathrm{Yu}$ ) independently performed the literature search, study selection, data extraction, and methodologic quality assessment. The disagreement was resolved in consultation with a third investigator (Haiting $\mathrm{Hu}$ ).

\section{Literature search}

A systematic literature search was conducted in PubMed, Cochrane, and Web of Science databases up to July 2019. We used "Starch/analogs and derivatives"[Mesh], resistant starch, Non-digestible starch, high amylose starch, fiber, "Lipids/blood" [Mesh], Triglycerides, triacylglycerol, cholesterol, lipid, low density lipoprotein, high density lipoprotein and "Clinical Study" [Publication Type] NOT "Observational Study" [Publication Type] OR random as search terms. Additionally, reference lists of original studies, recent reviews, and meta-analyses were also scrutinized. Clinical trials with resistant starch as intervention were included. The metabolic disorder enrolled volunteers were type 2 diabetes, overweight, and metabolic syndrome adults.A study that met the following criteria was included in the meta-analysis: (1) RCTs of either parallel or cross-over design; (2) the study assessed the impact of RS or standardized resistant starch-enriched carbohydrate on effect of blood lipids; (3) the study had an appropriate controlled design, e.g., if RS was administrated as an adjunct to another supplement, the control group received another carbohydrate supplement; and (4) the study provided available data to calculate the differences between baseline and endpoint on effect of blood lipids.

\section{Data extraction}

Predefined data were extracted from each report with the use of standardized forms. We extracted information on literature characteristics, such as the first author, publication year, country, sample-size, gender, mean age,health status, duration of intervention, study design, the dose of RS and control intake per day. Besides, the means and standard deviations (SDs) of TC, TG, HDL, and LDL at the endpoint in both intervention and control groups were extracted, respectively. The Cochrane score criteria were used for quality assessment, including the following items: (1)random sequence generation, (2)allocation concealment, (3)blinding of participants and personnel, (4)blinding of outcome assessment, (5)incomplete outcome data, (6)selective reporting. The units were converted to $\mathrm{mmol} / \mathrm{L}$ for blood lipids.

\section{Data synthesis}

A random-effects modelwas employed to calculate the pooled estimates. Heterogeneity between the studies was evaluated by $\mathrm{I}^{2}$ statistic. The $\mathrm{I}^{2}$ values of $25 \%, 50 \%$, and $75 \%$ were classified as low, moderate, and high degrees of heterogeneity,respectively. ${ }^{16}$ To identify the source of heterogeneity,subgroup analyses were performed to focus on information of the subjects: the dose of RS supplementation, duration of intervention,and disorder status of subjects. Statistical analysis was performed with RevMan5.3 software. Except as otherwise specified, $P<0.05$ was considered as statistically significant.

\section{RESULTS}

\section{Results of study selection}

The flow diagram of the literature search was shown in Figure 1. After the removal of 2736 duplicates, 3716 unique articles were retrieved. Of these, 3569 articles were deleted by screening the titles and abstracts, leaving 147 articles for full-text examination. After checking full-text, 141 articles were excluded because they did not meet the inclusive criteria (e.g., without providing available data,multi-component intervention, and study design). Ultimately, 6 articles were selected for inclusion and quantitative synthesis.

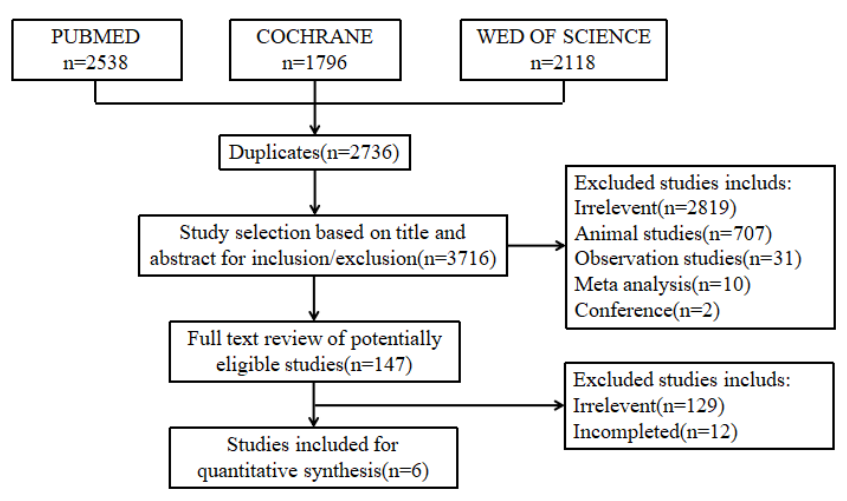

Figure 1 Flow diagram of the study selection procedure

\section{Study characteristics}

The characteristics of the 6 articles are shown in Table 1 .

Among them, 3 studies were conducted in UK (Bodinham et al., 2014; Robertson,et al., 2012; Bodinham et al., 2012), 2 in Asia (Gargari et al., 2015; Zhang et al., 2007), 1 in Oceania (Noakes et al., 1996). The sample-size of the subjects ranged from 12 to 60 , with a total of 320 participants. The dose of RS supplementation ranged 
Table 1 The Characteristics of the 6 eligible RCTs

\begin{tabular}{|c|c|c|c|c|c|c|c|c|c|}
\hline $\begin{array}{l}\text { Author' } \\
\text { Year }\end{array}$ & Country & $\begin{array}{c}\text { No. (In- } \\
\text { tervention/co } \\
\text { ntrol) }\end{array}$ & Gender(F/M); age & $\begin{array}{c}\text { Duration } \\
\text { (intervention/ } \\
\text { washout) }\end{array}$ & People & Intervention & Control & outcome & $\begin{array}{l}\text { Study } \\
\text { design }\end{array}$ \\
\hline $\begin{array}{l}\text { Bodinham, } \\
2014\end{array}$ & UK & $17(17 / 17)$ & $(5 / 12) ; 55 \pm 2.4$ & $\begin{array}{l}12 \text { weeks/ } \\
12 \text { weeks }\end{array}$ & $\begin{array}{c}\text { type } 2 \\
\text { diabetes }\end{array}$ & $\begin{array}{l}\mathrm{RS}^{1}(80 \mathrm{~g})+ \\
\operatorname{RDS}^{2}(54 \mathrm{~g})\end{array}$ & RS2(0g)+RDS(54g) & $\begin{array}{c}\mathrm{TG}^{4}, \mathrm{TC}^{5} \\
\mathrm{HDL}^{6}, \mathrm{LDL}^{7}\end{array}$ & crossover \\
\hline $\begin{array}{l}\text { Bodinham, } \\
2012\end{array}$ & UK & $12(12 / 12)$ & $(4 / 8) ; 37 \pm 4.0$ & $\begin{array}{l}4 \text { weeks/ } \\
4 \text { weeks }\end{array}$ & $\begin{array}{l}\text { overweight } \\
\text { people }\end{array}$ & $\begin{array}{l}\mathrm{RS} 2(40 \mathrm{~g})+ \\
\operatorname{RDS}(27 \mathrm{~g})\end{array}$ & $\mathrm{RS} 2(0 \mathrm{~g})+\mathrm{RDS}(27 \mathrm{~g})$ & TG, TC & crossover \\
\hline $\begin{array}{l}\text { Gargari, } \\
2015\end{array}$ & Iran & $60(28 / 32)$ & $\begin{array}{c}\text { (60/0); Control:49.6 } \\
\text { (8.4), Intervention: } \\
49.5(8.0)\end{array}$ & 8 weeks & $\begin{array}{c}\text { type } 2 \\
\text { diabetes }\end{array}$ & $\mathrm{RS} 2(10 \mathrm{~g})$ & maltodextrin $(10 \mathrm{~g})$ & $\begin{array}{c}\text { TG, TC, HDL, } \\
\text { LDL }\end{array}$ & parallel \\
\hline Zhang, 2007 & China & $40(20 / 20)$ & $\begin{array}{c}(23 / 17) ; 51.1 \pm 7.9 / \\
52.2 \pm 11.1\end{array}$ & $\begin{array}{c}4 \text { weeks/ } \\
1 \text { week }\end{array}$ & $\begin{array}{l}\text { type } 2 \\
\text { diabetes }\end{array}$ & $\mathrm{RS}^{3}(30 \mathrm{~g})$ & wheat flour (30g) & TG, TC & crossover \\
\hline $\begin{array}{c}\text { Noakes, } \\
1996\end{array}$ & Australia & a $23(23 / 23)$ & $(10 / 13) ; 44-64$ & $\begin{array}{c}4 \text { weeks/ } \\
0 \text { week }\end{array}$ & $\begin{array}{l}\text { overweight } \\
\text { people }\end{array}$ & $\begin{array}{c}\mathrm{RS}(30 \mathrm{~g} \text { for } \\
\text { women/ } \\
44.4 \mathrm{~g} \text { for men) }\end{array}$ & $\begin{array}{l}\text { Oat bran }(87 / 121 \mathrm{~g}) \text {, } \\
\text { low amylose starch } \\
(11-13 \mathrm{~g})\end{array}$ & $\begin{array}{c}\text { TG, TC, HDL, } \\
\text { LDL }\end{array}$ & crossover \\
\hline $\begin{array}{l}\text { Robertson, } \\
2012\end{array}$ & UK & $15(15 / 15)$ & $(7 / 8) ; 48.9 \pm 3.9$ & $\begin{array}{l}8 \text { weeks/ } \\
8 \text { weeks }\end{array}$ & $\begin{array}{l}\text { overweight } \\
\text { people }\end{array}$ & $\begin{array}{l}\mathrm{RS} 2(40 \mathrm{~g})+ \\
\operatorname{RDS}(27 \mathrm{~g})\end{array}$ & $\begin{array}{l}\mathrm{RS} 2(0 \mathrm{~g})+ \\
\operatorname{RDS}(27 \mathrm{~g})\end{array}$ & TG, TC & crossover \\
\hline
\end{tabular}

${ }^{1} \mathrm{RS} 2$, type 2 resistant starch derived from high amylose maize; ${ }^{2} \mathrm{RDS}$, rapidly digestible starch; ${ }^{3} \mathrm{RS}$, resistant starch; ${ }^{4} \mathrm{TC}$, total cholesterol; ${ }^{5} \mathrm{TG}$, triglyceride; ${ }^{6} \mathrm{HDL}$, high-density lipoprotein; ${ }^{7} \mathrm{LDL}$, low density lipoprotein.

from 10 to 80 g,and the duration of intervention lasted from 4 weeks to 12 weeks. One study has reported the different doses of RS for men and women, respectively (Noakes et al., 1996). Three studies were conducted in metabolic disorder subjects, including two studies with overweight subjects and one study with metabolic syndrome adults. Three studies were conducted in subjects with type 2 diabetes(T2DM).Five studies used cross-over design and one study used parallel design.

\section{Quality assessment}

The quality assessment of each study was conducted by the Cochrane Bias risk assessment[Figure 2]. Incomplete outcome data (attrition bias) and selective reporting (reporting bias) showed low risk, while random sequence generation (selection bias) and allocation concealment (selection bias) showed low risk partially with mostly unclear risk. However, blinding of participants and personnel (performance bias), blinding of outcome assessment (detection bias), and other bias showed low, unclear, high risk overall.

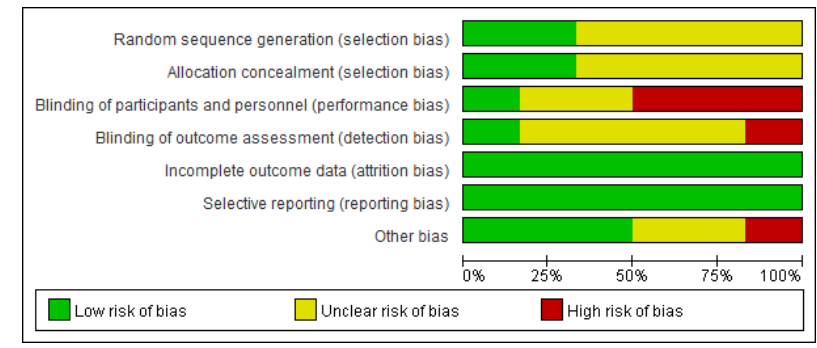

Figure 2 Quality assessment of the included studies

\section{Effect of RS on blood lipids}

\section{Effect of RS on TC}

All the trials provided available data on TC.The result showed that RS supplementation had no significant effect on TC concentration $(-0.28 \mathrm{mmol} / \mathrm{L} ; 95 \% \mathrm{CI}:-0.68$ to $0.12 \mathrm{mmol} / \mathrm{L} ; P=0.16)$, with a high between-study heterogeneity $\left(\mathrm{I}^{2}=94 \%\right)$ [Figure 3]. Therefore, the subgroup analysis could be conducted for further analysis.

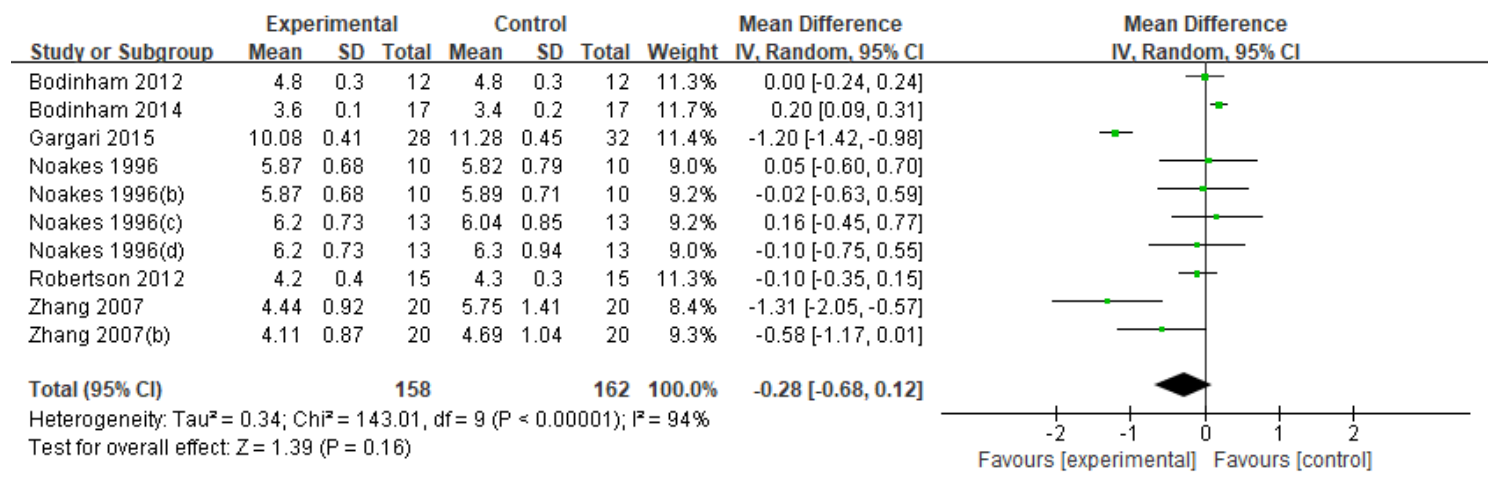

Figure3 Effect of RS intervention on TC concentrations 


\section{Effect of RS on $T G$}

All the trials provided available data on TG.The result showed that RS supplementation had no significant effect on TG concentration $(-0.42 \mathrm{mmol} / \mathrm{L}, 95 \% \mathrm{CI}:-1.02$ to $0.19 \mathrm{mmol} / \mathrm{L}, P=$ $0.18)$, with a high between-study heterogeneity $\left(\mathrm{I}^{2}=99 \%\right)$ [Figure 4]. Therefore, the subgroup analysis could be conducted for further analysis.

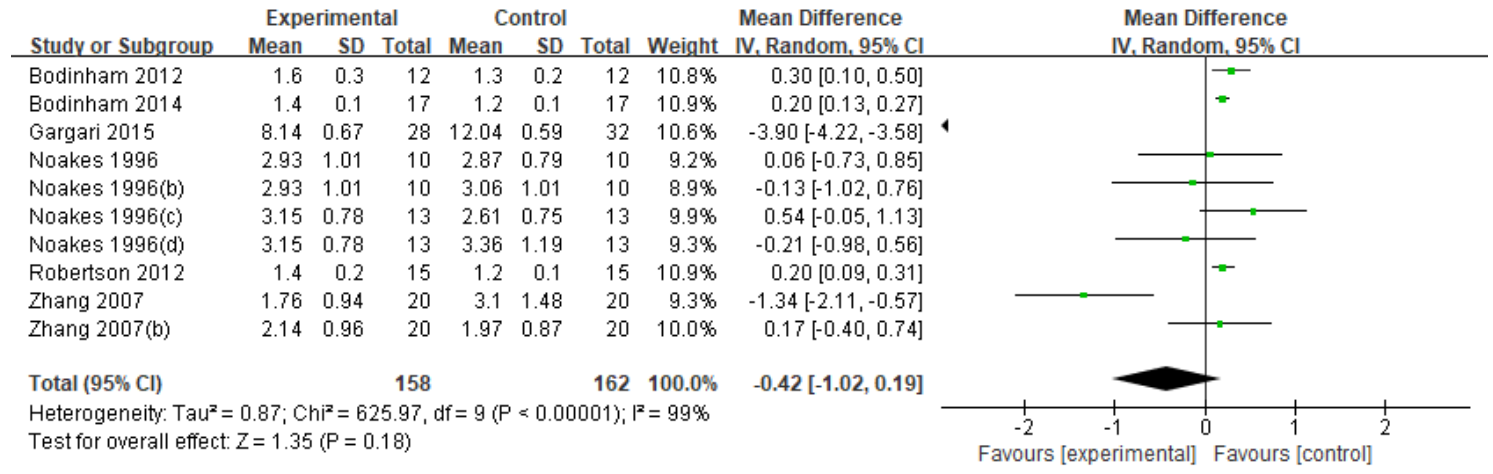

Figure 4 Effect of RS intervention on TG concentrations

\section{Effect of RS on HDL}

There are three studies containing six trails that provided available data on HDL.The result showed that RS supplementation had no significant effect on HDL concentration $(0.06 \mathrm{mmol} / \mathrm{L}, 95 \% \mathrm{CI}$ : -0.15 to $0.27 \mathrm{mmol} / \mathrm{L}, P=0.57)$, with a high between-study heterogeneity $\left(\mathrm{I}^{2}=96 \%\right)$ [Figure 5]. Therefore, the subgroup analysis could be conducted for further analysis.

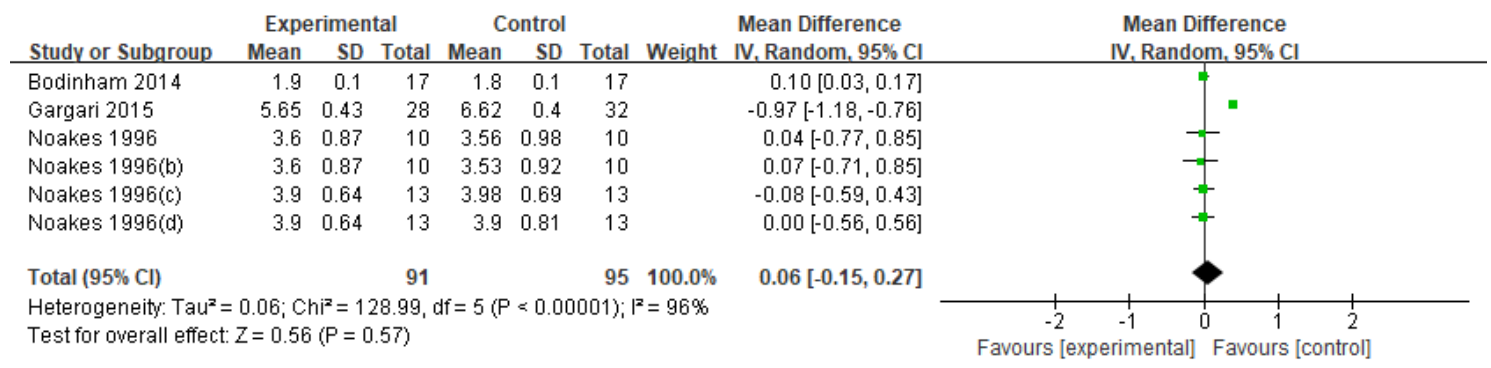

Figure 5 Effect of RS intervention on HDL concentrations

\section{Effect of RS on $L D L$}

There are three studies containing six trails that provided available data on LDL.The result showed that RS supplementation had no significant effect on LDL concentration $(-0.17 \mathrm{mmol} / \mathrm{L}, 95 \% \mathrm{CI}$ : -0.70 to $0.37 \mathrm{mmol} / \mathrm{L}, P=0.54)$, with a high between-study heterogeneity $\left(\mathrm{I}^{2}=94 \%\right)$ [Figure 6]. Therefore, the subgroup analysis could be conducted for further analysis.

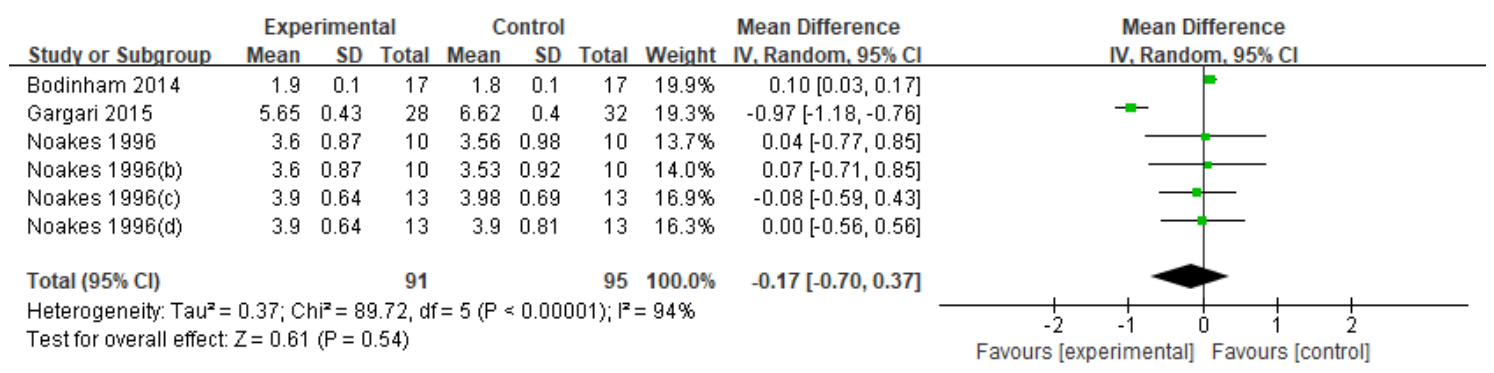

Figure 6 Effect of RS intervention on LDL concentrations

\section{Subgroup analysis}

To explore the sources of heterogeneity, subgroup analyses were conducted. For the included studies, the dose of RS supplementation, duration and disorder status were different, which may be the sources of heterogeneity, because differences in the dose and type of RS, duration of intervention, basal inflammatory/anti-inflammatory status, different comparison, ethnicity, and genotype may result on the contrary results. ${ }^{13}$ We used a dose of resistant starch of $30 \mathrm{~g}$ as the cutoff, and the results showed that the supplemental RS reduced the concentrations of TC $\left(-0.63 \mathrm{mmol} / \mathrm{L}, 95 \% \mathrm{CI}:-1.21,-0.04 ; \mathrm{I}^{2}=84 \%, P=0.04\right)$ when the dose is less than or equal to $30 \mathrm{~g}$, while increased the concentrations of TG $\left(0.21 \mathrm{mmol} / \mathrm{L}, 95 \% \mathrm{CI}: 0.15,0.26 ; \mathrm{I}^{2}=0 \%\right.$, 
$P<0.00001)$,LDL $\left(0.10 \mathrm{mmol} / \mathrm{L}, 95 \%\right.$ CI:0.03, $\left.0.16 ; \mathrm{I}^{2}=0 \%, P=0.005\right)$ when the dose is more than $30 \mathrm{~g}$. In addition, we set the disorder status as T2DM or overweight people. The results showed a increased effect on TG $\left(0.22 \mathrm{mmol} / \mathrm{L}, 95 \%\right.$ CI:0.12, $0.31 ; \mathrm{I}^{2}=0 \%$, $P<0.00001)$ in the overweight people. There were no significant effects on other subgroups except the above results [Table 2].

Table 2 Subgroup analyses for TC, TG, HDL and LDL concentrations.

\begin{tabular}{|c|c|c|c|c|c|c|c|c|c|c|c|c|c|c|c|c|}
\hline \multirow{3}{*}{ Factors stratified } & \multicolumn{4}{|c|}{$\mathrm{TC}$} & \multicolumn{4}{|c|}{ TG } & \multicolumn{4}{|c|}{ HDL } & \multicolumn{4}{|c|}{ LDL } \\
\hline & \multirow{2}{*}{ No. } & \multirow{2}{*}{$95 \% \mathrm{CI}$} & \multicolumn{2}{|c|}{ Heterogeneity } & \multirow[t]{2}{*}{ No } & \multirow{2}{*}{$95 \% \mathrm{CI}$} & \multicolumn{2}{|c|}{ Heterogeneity } & \multirow[t]{2}{*}{ No. } & \multirow{2}{*}{$95 \% \mathrm{CI}$} & \multicolumn{2}{|c|}{ Heterogeneity } & \multirow[t]{2}{*}{-No } & \multirow{2}{*}{$95 \% \mathrm{CI}$} & \multicolumn{2}{|c|}{ Heterogeneity } \\
\hline & & & $\mathrm{I}^{2}(\%)$ & $P$ & & & $\mathrm{I}^{2}(\%)$ & $P$ & & & $I^{2}(\%)$ & $P$ & & & $\mathrm{I}^{2}(\%)$ & $P$ \\
\hline \multicolumn{17}{|l|}{$\begin{array}{l}\text { Dose of resistant } \\
\text { starch }\end{array}$} \\
\hline$\leq 30 \mathrm{~g}$ & 5 & $-0.63(-1.21,-0.04)$ & 84 & 0.04 & 5 & $-1.04(-3.10,1.02)$ & 98 & 0.32 & 3 & $0.12(-0.21,0.46)$ & 92 & 0.47 & 3 & $-0.36(-1,18,0.46$ & 6) 82 & 0.39 \\
\hline$>30 \mathrm{~g}$ & 5 & $0.07(-0.08,0.22)$ & 38 & 0.36 & 5 & $0.21(0.15,0.26)$ & $0<$ & $<0.00001$ & 3 & $-0.00(-0.06,0.05)$ & 0 & 0.96 & 3 & $0.10(0.03,0.16)$ & 0 & 0.005 \\
\hline \multicolumn{17}{|l|}{ Duration } \\
\hline$<8$ weeks & 7 & $-0.21(-0.53,0.11)$ & 58 & 0.20 & 7 & $-0.02(-0.42,0.37)$ & 69 & 0.91 & 4 & $-0.01(-0.09,0.07)$ & 0 & 0.78 & 4 & $-0.01(-0.33,0.30$ & 0) 0 & 0.94 \\
\hline$\geq 8$ weeks & 3 & $-0.36(-1.23,0.50)$ & 98 & 0.41 & 3 & $-1.15(-2.39,0.10)$ & 100 & 0.07 & 2 & $0.20(-0.19,0.58)$ & 99 & 0.32 & 2 & $-0.43(-1.48,0.62$ & 2) 99 & 0.42 \\
\hline \multicolumn{17}{|l|}{$\begin{array}{l}\text { Type of } \\
\text { participants }\end{array}$} \\
\hline $\mathrm{T} 2 \mathrm{DM}$ & 4 & $-0.70(-1.64,0.24)$ & 98 & 0.14 & 4 & $-1.22(-3.58,1.14)$ & 100 & 0.31 & 2 & $-0.01(-0.09,0.07)$ & 0 & 0.78 & 4 & $-0.01(-0.33,0.30$ & 0 & 0.94 \\
\hline Overweight & 6 & $-0.03(-0.18,0.12)$ & 0 & 0.70 & 6 & $0.22(0.12,0.31)$ & $0<$ & $<0.00001$ & 2 & $0.20(-0.19,0.58)$ & 99 & 0.32 & 2 & $-0.43(-1.48,0.62$ & 2) 99 & 0.42 \\
\hline
\end{tabular}

Abbreviations: CI, confidential interval; T2DM; type 2 diabetes mellitus.

\section{DISCUSSION}

\section{Summary of evidence}

In recent researches, some reported that RS did not lower serum lipid concentrations, ${ }^{12,18,19}$ while several investigators have proposed RS as a new category of dietary fiber possessing some metabolic functions against abnormality caused by an extra supply of energy or fat. ${ }^{20-24}$ Since RS remains mostly undigested until it is partially fermented in the colon, the metabolism of RS appears to occur 5-7 h after consumption in contrast to normally cooked starch which is digested almost immediately. ${ }^{25}$

From the previous studies, RS played a useful role in health by some potential mechanisms include: (1) changes in intestinal microbiota, (2) a reduction in insulin, (3) resistance rise in HDL-c concentrations, and (4) an increase in SCFAs production. ${ }^{3-6,26-34} \mathrm{RS}$ could produce SCFAs through two pathways: directly (RS fermentation) or indirectly (increasing colonic butyrate-producing microbiota such as Lachnospiraceae and Ruminococcaceae). Butyrate can control macrophage activity and expression of NF- $\kappa \mathrm{B}$ which is the main inflammatory and immune response. Additionally, it can raise the expression of cytokine signaling 3 suppressors (SOCS 3), secretion of IL-10, reduce the expression of pyrogenic factors (e.g., Myeloperoxidase) and IL-12 level. ${ }^{35}$ Recent research showed that butyrate could regulate the release of GLP-1 through its central and peripheral targets. ${ }^{32,34,36}$ However, Castillo et al. reported that consumption of native banana starch supplementation $(24 \mathrm{~g} / \mathrm{d})$ as a rich source ofRS2 for 4 weeks did not affect the lipid profile, HbAlc and FBS and insulin resistance in obeseT2DM patients. ${ }^{37}$

Therefore, it is meaningful to investigate the effect of RS on blood lipids to obtain relatively reliable evidence. However, in this meta-analysis article, RS supplementation showed no significant effects on TC, TG, HDL, and LDL with high heterogeneity. The high heterogeneity may result from the different dose of RS, different duration and disorder status, because there were some conclusions showed that differences in the dietary intake (RS, macronutrient, total fiber), dose and type of RS, basal inflammatory/anti-inflammatory status, duration of intervention, ethnicity and genotype may result on the contrary results. ${ }^{17}$

However, we conducted a subgroup analysis to analyze the source of high heterogeneity. Data from the current meta-analysis of 6articles (in 320 participants) showed thatRS supplementation had decreased effect on TC concentration when the dose of RS was less than or equal to $30 \mathrm{~g}$, but had increased effect on TG and LDL concentration when the dose of RS was more than $30 \mathrm{~g}$. These results may be explained from that the RS does not seem to bind to bile acids, so the more intake may not have a significant effect on blood lipids. ${ }^{11,12}$ Another reason may be the limited SCFA concentrations increased by RS. Because some studies had reported that SCFA does not discount a change in fecal/luminal concentrations, which may be involved in the increased stimulation of GLP1 through the FFAR 2/3 receptor. ${ }^{32,34,38}$ Additionally, some researches had reported that RS2 could not improve human health as expected because of its instability by gelatinization as natural starch granules. ${ }^{31,39}$ The result suggested that the supplementation of RS was not useful to control blood lipids in overweight people with no drug treatment, which may be due to the shorter duration of fewer than 8 weeks. Meanwhile, it was verified RS could increase TG concentration no matter dose or duration. However, the result showed that there was no significant effect on HDL concentration no matter the dose of RS, the intervention time, or the disorder status of people.

\section{Limitations and future research needs}

The present meta-analysis provided substantial evidence of RS supplementation on blood lipids in metabolic disorder adults for the first time. However, there may be some reasons for the poor results. First, there was publication bias in the six articles, which may be affect the result that we obtained. Another possible reason was that the included studies were limited because the relevant 
articles were fewer, which resulted in a high heterogeneity. However, in subgroup analysis, the number of some subgroups included in the study were very few, which the results provided may not be true. Therefore, further focus on the RCTs or observation studies of RS effects on blood lipids, including the different types and more results should be conducted.

\section{CONCLUSION}

In conclusion, the results of this study showed that in metabolic disorder people, RS supplementation had decreased effect on TC concentration when the dose of RS was less than or equal to $30 \mathrm{~g} / \mathrm{d}$, but had increased effect on TG and LDL concentration when the dose of RS was more than $30 \mathrm{~g} / \mathrm{d}$, while there was no significant effect on HDL concentration no matter the dose of RS or the intervention time. However, with the limits of this meta-analysis, there will be more focus on the further researches, which are relevant to the effect of RS on blood lipids, including different type of RS in order to obtain a new viewpoint on how the supplement of RS affect the blood lipids concentration in metabolic disorder people.

\section{REFERENCES}

1. Garcia C, Feve B, Ferre P. Diabetes and inflammation: fundamental aspects and clinical implications. Diabetes Metab 2010; 36(5): 327-38.

2. Homayouni A, Amini A, Khodavirdivand A. Resistant starch in food industry: A changing outlook for consumer and producer. Starch 2014; 66(1-2): 102-14.

3. Laure B. Bindels, Rafael R. Segura Munoz1, João Carlos Gomes-Neto, et al. Resistant starch can improve insulin sensitivity independently of the gut microbiota. Microbiome 2017; 5:12.

4. Tao Li, Hui Teng, Fengping An, et al. The beneficial effects of purple yam (Dioscorea alata L.) resistant starch on hyperlipidemia in high-fat-fed hamsters. Food Funct 2019; 10: 2642-2650.

5. Wahjuningsih SB, Haslina H, Marsono M. Hypolipidaemic Effects of High ResistantStarch Sago and Red Bean Flour- based Analog Rice on Diabetic Rats. Mater Sociomed 2018; 30(4): 232-239.

6. Matsuda H, Kumazaki K, Otokozawa R, et al. Resistantstarch suppresses postprandial hypertriglyceridemia in rats. Food Res Int 2016; 89(Pt 1): 838-842.

7. de Deckere EAM, Kloots WJ, van Amelsvoort JMM. Resistant starch decreases serum total cholesterol and triacylglycerol concentrations and fat accretion in the rat. Br J Nutr 1993; 73: 74-76.

8. de Deckere EAM, Kloots WJ, van Amelsvoort JMM. Both raw and retrograded starch decrease serum triacylglycerol concentration and fat accretion in the rat. Br J Nutr 1995; 72: 287-298.

9. Younes H, Levrat MA, Demigne C, Remesy C. Resistant starch is more effective than cholestyramine as a lipid-lowering agent in the rat. Lipids 1995;30:847-853.

10. Vanhoof K, de Schrijver R. Consumption of enzyme-resistant starch and cholesterol metabolism in normo and hypercholesterolemic rats. Nutr Res1997;17: 1331-1340.

11. Levrat MA, Moundras C, Younes H, Morand C, Demigne C, Remesy C. Effectiveness of resistant starch, compared to guar gum, in depressing plasma cholesterol and enhancing fecal steroid excretion. Lipids 1996; 31: 1069-1075.

12. Heijnen MA, van Amelsvoort JMM, Deurenberg P, Beynen AC. Neither raw nor retrograded resistant starch lowers fasting serum cholesterol concentrations in healthy normolipidemic subjects. Am J Clin Nutr 1996; 64: 312-318.
13. Marchini JS, Faisant N, Champ M, Ranganathan S, Azou.lay C, Kergueris MF, Piloquet $\mathrm{H}$, Krempf $\mathrm{M}$. Effects of an acute raw resistant potato starch supplement on postprandial glycemia, insulinemia, lipidemia in healthy adults. Nutr Res 1998; 18: 1135-1145.

14. van Munster IP, Tangerman A, Nagengast FM. Effect of resistant starch on colonic fermentation, bile acid metabolism, and mucosal proliferation. Dig Dis Sci 1994;39: 834-842.

15. Phillips J, Muir JG, Birkett A, Lu ZX, Jones GP, O’Dea K, Young GP. Effect of resistant starch on fecal bulk and fermentation-dependent events in humans. Am J C1 in Nutr 1995;62: 121-130.

16. Higgins JPT, Green S. Cochrane Handbook for SystematicReviews of Interventions. Version 5.1.0. Available: http://www.cochrane-handbook. org. Accessed May 5, 2012.

17. Bahram Pourghassem Gargaria, Nazli Namazib, Mohammad Khalilic, Bahreh Sarmadid, Mohammad Asghari Jafarabadi, Parvin Dehghan. Is there any place for resistant starch, as alimentary prebiotic, for patients with type 2 diabetes? Complementary therapies in medicine 2015; 23: 810-815.

18. Jenkens DJ, Vuksan V, Kendall CW, Wursch P, Jeffcoat R, Waring S, Mehling CC, Vidgen E, Augustin LS, Wong E. Physiological effects of resistant starches on fecal bulk, short chain fatty acids, blood lipids and glycemic index. J Am Coll Nutr 1998; 17: 609-616.

19. Noakes M, Clifton PM, Nestel PJ, LeLeu R, McLntosh G. Effect of high-amylose starch and oat bran on metabolic variable and bowel function in subjects with hypertriglyceridemia. Am J Clin Nutr 1996; 64: 944-951.

20. Bornet F. Technological treatments of cereals. Discussions on the physiological properties of starch. Curb Polymers 1993;21: 195-203.

21. CL Bodinham, L Smith, EL Thomas, JD Bell, JR Swann, A Costabile, D Russell-Jones, AM Umpleby and MD Robertson. Efficacy of increased resistant starch consumption in human type 2 diabetes. Endocrine Connections 2014; 3: 75-84.

22. Caroline L. Bodinham, Leanne Smith, John Wright, Gary S. Frost, M. Denise Robertson. Dietary Fibre Improves First-phase Insulin Secretion in Overweight Individuals. Plos One 2012; 7: 1-5.

23. M. Denise Robertson, John W. Wright, Emmanuelle Loizon, Cyrille Debard, Hubert Vidal, Fariba Shojaee-Moradie, David Russell-Jones, and A. Margot Umpleby. Insulin-Sensitizing Effects on Muscle and Adipose Tissue after Dietary Fiber Intake in Men and Women with Metabolic Syndrome. J Clin Endocrinol Metab 2012; 97: 3326-3332.

24. Zhang WQ, Zhang HW, Zhang YM, Yang YX. Effects of resistant starch on insulin resistance of type 2 diabetes mellitus patients. Chin J of Prev Med 2007; 41: 101-104.

25. Muir JG, Lu ZX, Young GP, Cameron SD, Collier GR, O’Dea K. Resistant starch in the diet increases breath hydrogen and serum acetate in human subjects. Am J Clin Nutr 1995;61: 792-799.

26. Weisstaub AR, Salinas MV , Correa MJ, et al. Effects of the intake of white wheat bread added with garlic and resistantstarch: action on calcium bioavailability and metabolic parameters of growing Wistar rats. Food Funct 2018; 9(11): 5707-5714.

27. Alfa MJ, Strang D, Tappia PS, et al. A Randomized Placebo Controlled Clinical Trial to Determine the Impact of Digestion Resistant Starch MSPrebiotic $^{\circledR}$ on Glucose, Insulin, and Insulin Resistance in Elderly and Mid-Age Adults.Front Med (Lausanne) 2018; 22(4): 260.

28. Sun H, Ma X, Zhang S, et al. Resistant starch produces antidiabetic effects by enhancing glucose metabolism and ameliorating pancreatic dysfunction in type 2 diabetic rats.Int J Biol Macromol 2018; 110: 276-284.

29. Sandberg JC, Björck IME, Nilsson AC. Effects of whole grain rye, with and without resistant starch type 2 supplementation, on glucose 
tolerance, gut hormones, inflammation and appetite regulation in an 11-14.5 hour perspective; a randomized controlled study in healthy subjects.Nutr J 2017; 16(1): 25.

30. Hedemann MS, Hermansen K, Pedersen S, et al. ResistantStarch but Not Enzymatically Modified Waxy Maize Delays Development of Diabetes in Zucker Diabetic Fatty Rats. J Nutr 2017; 147(5): 825-834.

31. Bergeron N, Williams PT, Lamendella R, et al. Diets high in resistantstarch increase plasma levels of trimethylamine-N-oxide, a gut microbiome metabolite associated with CVD risk. Br J Nutr 2016; 116(12): 2020-2029.

32. Rahat-Rozenbloom S, Fernandes J, Cheng J, et al. The acute effects of inulin and resistant starch on postprandial serum short-chain fatty acids and second-meal glycemic response in lean and overweight humans.Eur J Clin Nutr 2017; 71(2): 227-233.

33. Dainty SA, Klingel SL, Pilkey SE, et al. Resistant Starch Bagels Reduce Fasting and Postprandial Insulin in Adults at Risk of Type 2 Diabetes.J Nutr 2016; 146(11): 2252-2259.

34. Upadhyaya B, McCormack L, Fardin-Kia AR, et al. Impact of dietary resistant starch type 4 on human gut microbiota and immunometabolic functions.Sci Rep 2016; 6:28797.

35. Segain JP, De La Blatiere DR, Bourreille A. Butyrate inhibits inflammatory responses through NFK-B inhibition: implications for Crohn's disease. Gut 2000; 47: 397-403.

36. McOrist AL, Miller RB, Bird AR, et al. Fecal butyrate levels vary widely among individuals but are usually increased by a diet high in resistant starch. J Nutr 2011; 141: 883-889.

37. Levrat MA, Moundras C, Younes H, Morand C, Demigne C, Remesy C. Effectiveness of resistant starch, compared to guar gum, in depressing plasma cholesterol and enhancing fecal steroid excretion. Lipids 1996;31: 1069-1075.

38. Zhang L, Li HT, Shen L, et al. Effect of Dietary ResistantStarch on Prevention and Treatment of Obesity-related Diseases and Its Possible Mechanisms. Biomed Environ Sci 2015; 28(4):291-297.

39. Keenan MJ, Zhou J, Hegsted M, et al. Role of resistantstarch in improving gut health, adiposity, and insulin resistance. Adv Nutr 2015; 6(2):198-205. 